\title{
MOORING BRIDGE CAISSONS DURING CONSTRUCTION USING JETTED-IN DRIVEN PLATE ANCHORS
}

\author{
Osama A. Safaqah, Ph.D., Ben C. Gerwick, Inc. San Francisco, CA \\ Marc Gerin, Ph.D., P.E. Ben C. Gerwick, Inc. San Francisco, CA \\ Robert Bittner, P.E., Ben C. Gerwick, Inc. San Francisco, CA
}

\begin{abstract}
Driven plate anchors can be used to hold in place large bridge caissons during floating construction. Their small size and simple method of installation make them a very cost effective alternative to other direct-embedment, gravity, and drag anchors. The geotechnical design of plate anchors involves the anchor geometry, embedment, drivability, and proof testing. This paper describes the experience gained with plate anchors used during construction of the new Tacoma Narrows Bridge. For this project, the anchors had to be driven in dense to very dense sands, and had to resist large forces from 7-9 knot currents.
\end{abstract}

\section{INTRODUCTION}

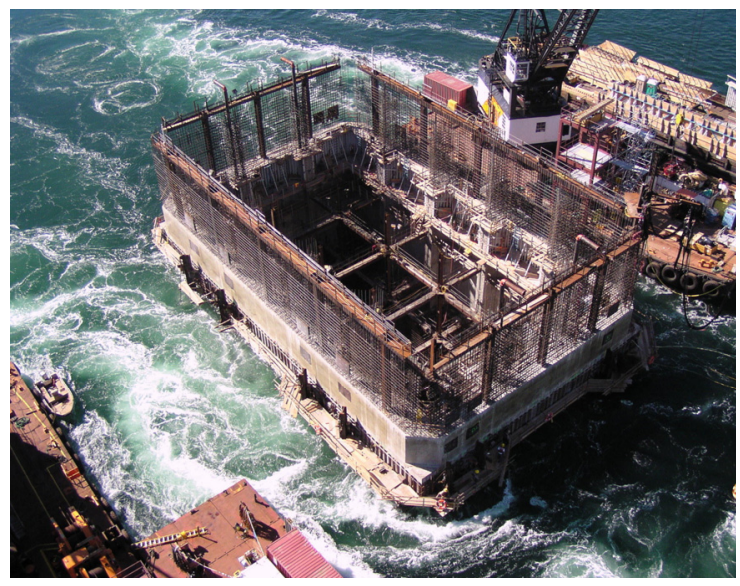

Figure 1: Floating Caisson held in Position by Anchors.

Driven plate anchors are conceptually very simple: as shown in Fig. 2, plate anchors consist of a steel plate welded onto a section of structural steel beam to which a padeye is attached. As shown in Fig. 3, the anchor is connected to a follower (H-Pile) by a hydraulic clamp and is driven vertically into the sea floor using an under-water hammer. After driving the anchor to the required depth, the follower is retrieved and the anchor is proof-tested. This will cause the anchor to rotate to the horizontal or "key in" thus developing maximum resistance to pull out (Fig. 3).
Driven plate anchors are simple, inexpensive, quick to install and have a very high holdingcapacity-to-weight ratio compared to other underwater anchor systems. This makes them very suitable for the temporary mooring of bridge caissons during their construction.

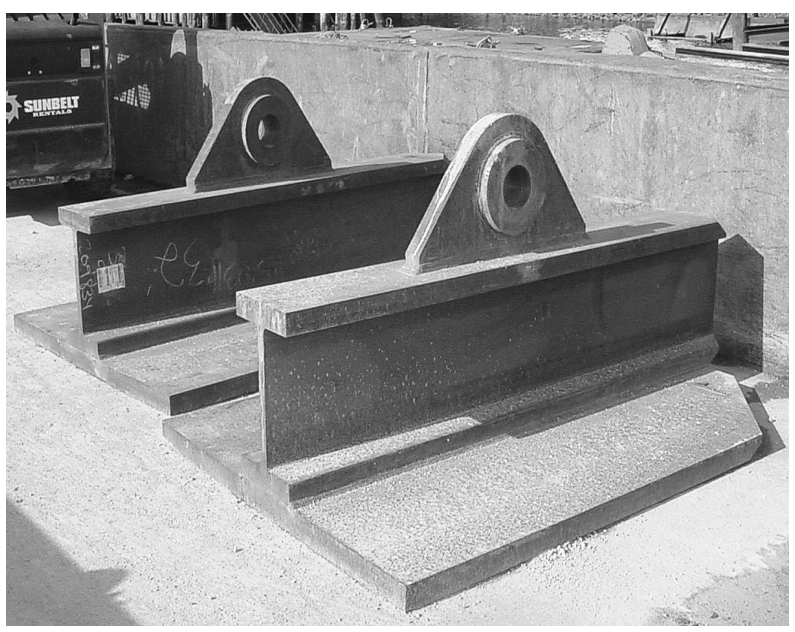

Figure 2: Driven Plate Anchor 


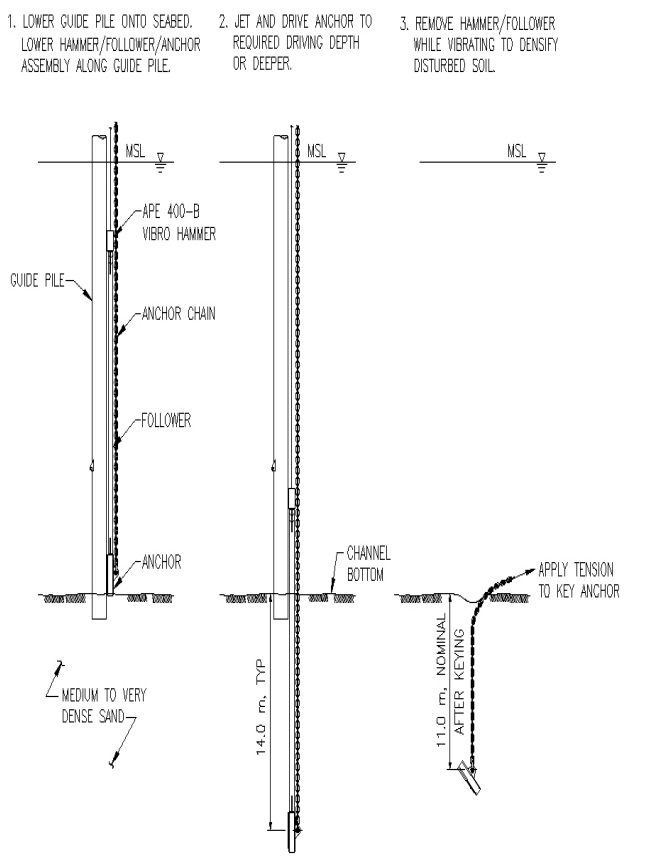

Figure 3a: Plate Anchor Concept and Installation Procedure

The driven plate anchor design described in this paper was developed for the construction of the new Tacoma Narrows Bridge. The Narrows is a deep waterway located at the south end of Puget Sound, on the West coast of Washington State. The deepest point along the bridge alignment is about $-67 \mathrm{~m}(-220 \mathrm{ft})$ elevation, and the tidal currents are very fast (7-9 knots) between tidal shifts. The new 1-mile long suspension bridge is supported by two main towers. These towers are founded on two $24 \times 40$ $\mathrm{m}(80 \times 130 \mathrm{ft})$ caissons embedded $23 \mathrm{~m}(75 \mathrm{ft})$ below the mudline in 40-46 m (130-150 ft) of water. The concrete caissons were constructed from a "raft" which was cast in a dry-dock, towed to the site and moored in place. The remaining concrete was cast-in-place in $3 \mathrm{~m}$ (10 ft) lifts. Until the bottom of the caissons reached the seabed, the floating caissons had to be moored in place.

The mooring system for the bridge caissons had

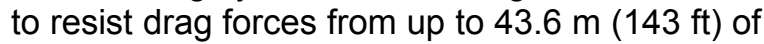
draft in 7-9 knots maximum tidal currents. Each caisson was moored by 16 lower anchors on a nominal 300 -ft radius and 16 upper anchors on a nominal $600-\mathrm{ft}$ radius. At the caisson end, the lower lines are attached approximately $7.6 \mathrm{~m} \mathrm{(25}$ $\mathrm{ft}$ ) up from the bottom of each caisson and remain fixed during construction. The upper lines are initially installed approximately $18.3 \mathrm{~m}$
$(60 \mathrm{ft})$ up from the bottom of each caisson. They are attached to a sliding beam, which is moved upward as the caisson is constructed. The lower mooring lines were $100 \mathrm{~mm}$ (4 in) diameter OilRig-Quality stud-link chain and the upper lines were $95 \mathrm{~mm}$ (3.75 in) diameter bridge strand connected to one shot of $100 \mathrm{~mm}$ (4 in) chain. Each of the 64 mooring lines was attached to a driven plate anchor. See Figure $3 b$ and $3 c$ for schematic of anchor attachment to caisson.

\section{GEOTECHNICAL DESIGN OF PLATE ANCHORS}

Anchors can have either a "shallow" or a "deep" mode of failure depending on the embedment ratio $(H / B$, anchor depth to anchor smallest dimension), and the soil friction angle. In a "shallow" failure, the failure surfaces extend to the ground surface at small anchor displacements. This mode of failure results in the lowest anchor capacity. In a deep failure, failure starts locally around the anchor like bearing failure around a footing. Global failure takes place at large displacements with an inverted-pyramid-shaped rupture surface. This failure mode results in a much higher anchor capacity. Plate anchors are designed to develop a "deep" type of failure.

Plate anchor capacity in sands can be theoretically estimated using the following equation:

$q_{u}=\gamma^{\prime} H N_{q}^{*}$

where $\gamma^{\prime}, H$, and $N_{q}{ }^{*}$ are the effective unit weight of soil, embedment length, and anchor capacity factor, respectively. Obtaining a reasonably accurate estimate of $N_{q}{ }^{*}$ is the major task in designing plate anchors. This is because it depends on many factors including anchor orientation, embedment ratio, soil dilatancy, anchor roughness, soil angle of friction, and initial stress state. Further, the anchor installation method has an impact on the angle of friction and the stress state, which must be considered. 


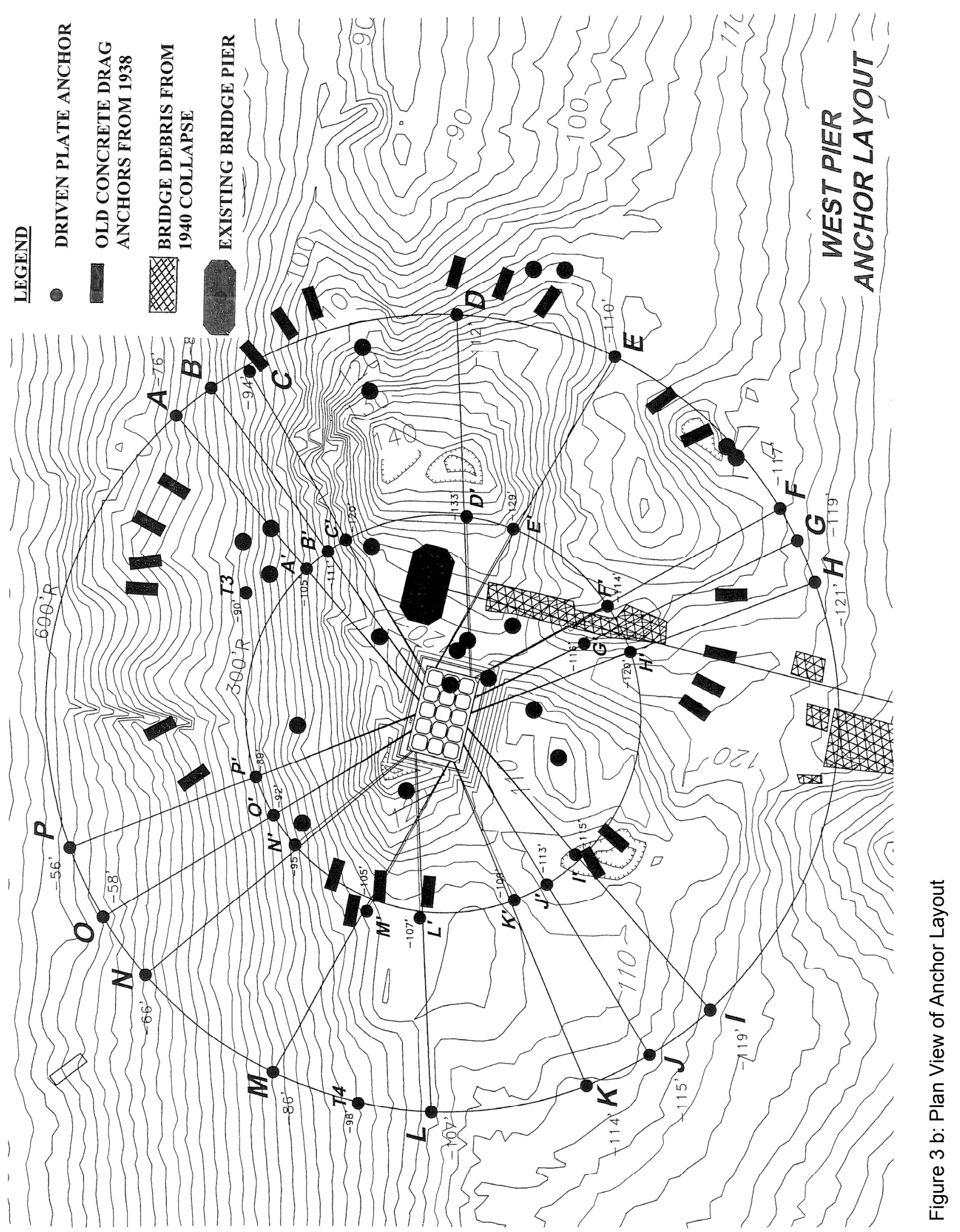




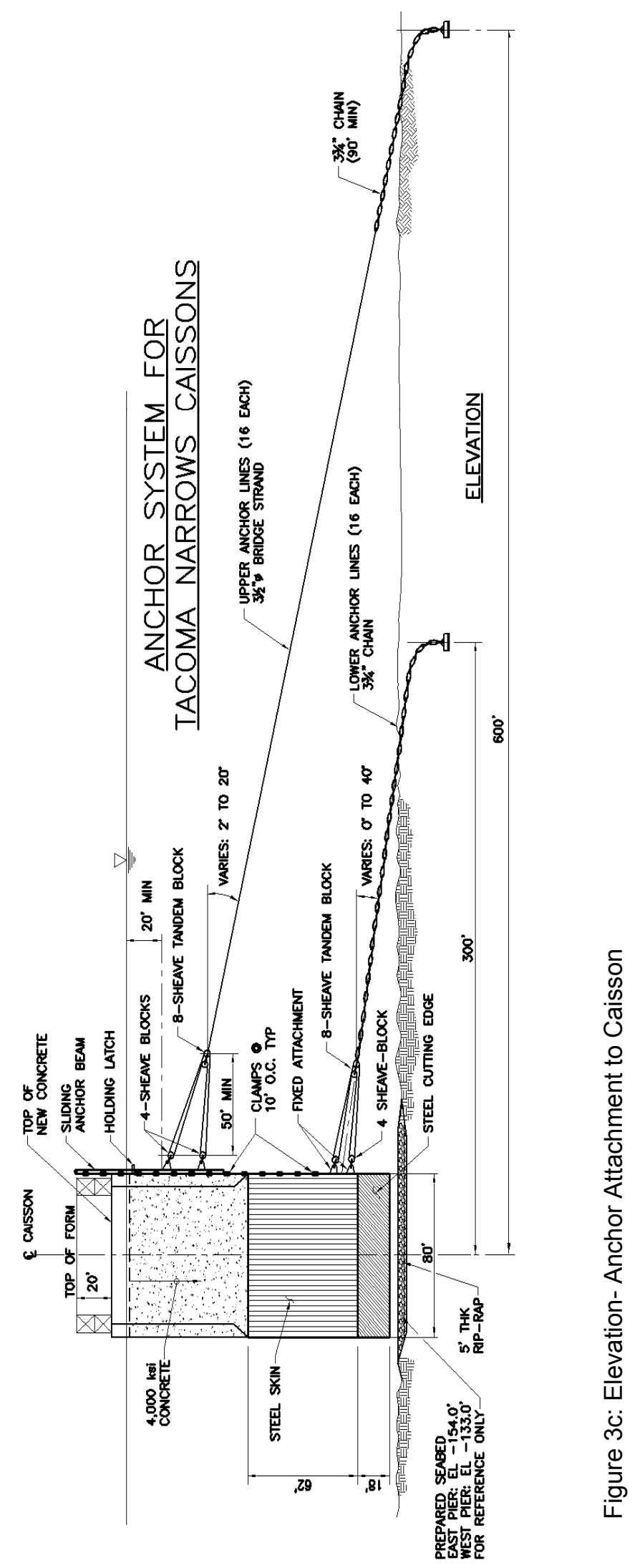


Many methods have been proposed to estimate $N_{q}{ }^{*}$. Some are based on assumed failure mechanisms, some are based on small-scale centrifuge tests, and some are based on largescale pull out tests. Unfortunately, $N_{q}{ }^{*}$ values estimated from these methods range from very conservative to very optimistic. The Majer (1955) method is based on a vertical slip failure surface and usually represents a lower, very conservative, limit on $N_{q}{ }^{*}$. On the other hand, the Meyerhof and Adams (1968) method is based on a pyramid-shaped failure surface and results in upper estimates of $N_{q}{ }^{*}$, however, these can be unconservative in dense sands. Other methods include Vesic (1972), based on the cavity expansion concept, and Vermeer and Sutjiadi (1985), which uses soil dilatancy to control the shape of the failure surface. A reasonable analytical method was proposed by Rowe and Davis (1982). They used two-dimensional finite element analyses with an elasto-plastic soil model to develop plate anchor design charts. Their model accounts for soil dilatancy, initial stress state and anchor roughness.

Perhaps the best approach to plate anchor design is one based on an empirical method calibrated with full-scale tests, and augmented with analytical analysis. The Navy design charts (Forrest et al., 1995) are well calibrated with fullscale field tests, and represent a good staring point. These charts relate the holding capacity factor $\left(N_{q}{ }^{*}\right)$ to the anchor embedment ratio, and the soil friction angle.

\section{SITE CONDITIONS}

At the West tower, the mudline elevation is

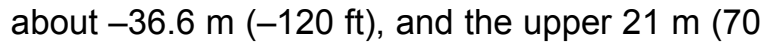
$\mathrm{ft}$ ) of soil consists of very dense, gravelly sand and sandy gravel. At the East tower, the mudline elevation varies between $-36.6 \mathrm{~m}$ and $-48.8 \mathrm{~m}$, and the upper $14 \mathrm{~m}(50 \mathrm{ft})$ of soil consists of medium dense to very dense gray silty fine sand.

Because of the dense soil conditions at the site, driving is aided by jetting ahead of the anchor. The jetting process will disturb the soil around the anchor reducing the friction angle, however, part of this loss can be recovered by using the vibro-hammer to compact the soil during retrieval of the follower. Table 1 shows the soil properties used in the design of the plate anchors.

TABLE No. 1 Soil properties used in the design of the plate anchors

\begin{tabular}{|c|c|c|c|}
\hline $\begin{array}{l}\text { Location } \\
\text { (1) }\end{array}$ & $\begin{array}{l}\text { Condition } \\
\text { (2) }\end{array}$ & $\begin{array}{l}\text { Friction } \\
\text { Angle, } \phi \\
\text { (degrees) } \\
(3)\end{array}$ & $\begin{array}{l}\text { Buoyant } \\
\text { Unit } \\
\text { Weight, } \\
\gamma_{\mathrm{b}} \\
\left(\mathrm{kN} / \mathrm{m}^{3}\right) \\
(4)\end{array}$ \\
\hline $\begin{array}{l}\text { West } \\
\text { Tower }\end{array}$ & Undisturbed & 38 to 40 & 10.4 \\
\hline $\begin{array}{l}\text { West } \\
\text { Tower }\end{array}$ & $\begin{array}{l}\text { After Jetting } \\
\text { and Vibro- } \\
\text { compaction }\end{array}$ & 35 & 9.4 \\
\hline $\begin{array}{l}\text { East } \\
\text { Tower }\end{array}$ & & 36 to 38 & 10.4 \\
\hline $\begin{array}{l}\text { East } \\
\text { Tower }\end{array}$ & $\begin{array}{l}\text { After Jetting } \\
\text { and Vibro- } \\
\text { compaction }\end{array}$ & 35 & 9.4 \\
\hline
\end{tabular}

\section{DESIGN AND INSTALLATION OF PLATE}

\section{ANCHORS}

The plate anchor dimensions and embedment depth were selected to provide a holding capacity of $4450 \mathrm{kN}$ (1000 kip) at the mudline with a factor of safety of two. The chain embedded in the sand typically contributes at least $20 \%$ of the total capacity, therefore, the plate anchor itself was designed to provide 3560 kN (800 kip) capacity with a factor of safety of two. Using the Navy charts and the Rowe and Davis method, $N_{q}{ }^{*}$ was estimated at 20 (Other methods gave values ranging from 7 to 40 ). The analysis showed that an embedment ratio of 7 is needed to ensure a deep failure mode at this site.

The anchors consist of a $75 \mathrm{~mm}$ ( 3 in) thick steel plate $2.4 \mathrm{~m} \times 1.5 \mathrm{~m}(8 \mathrm{ft} \times 5 \mathrm{ft})$ welded to an 2.4 $\mathrm{m}(8 \mathrm{ft})$ long piece of $\mathrm{W} 18 \times 311$ structural steel beam (Fig. 2). The driving end of the plate and beam are beveled at 45 degrees. A $75 \mathrm{~mm}$ (3 in) thick padeye welded onto the beam provides the attachment point for the $100 \mathrm{~mm}$ (4 in) stud-link chain.

For a plate width of $1.5 \mathrm{~m}(5 \mathrm{ft})$, the required embedment depth is $10.5 \mathrm{~m}$ (35 ft) after "keyingin". The distance the anchor travels to rotate and key in is a function of the soil friction angle, proof load orientation, and the configuration and 
length of the anchor. Denser soils and smaller anchors require smaller keying distance. As a rule of thumb, plate anchors in sands require 1.5 times their length to key in. Therefore, the minimum driving depth for the Tacoma Narrows

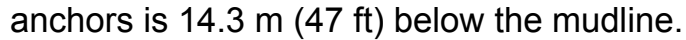

The anchors are installed using a $18.3 \mathrm{~m} \mathrm{(60 \textrm {ft } )}$ follower (a W14×342 steel beam) with an APE 400 vibratory hammer mounted at the top, and a hydraulic clamp mounted at the bottom. Drivability analyses were used to select the hammer and to optimize the design to four water jets at $2400 \mathrm{kPa}$ (350 psi) pressure. The water jets help loosen the sand making vibration more effective. A hydraulic clamp was used to hold the anchor during driving, instead of a passive attachment, to maximize the transfer of vibration from the follower to the anchor, See Figure 4. After delivering the anchor to the required depth, the follower was retrieved under vibration in

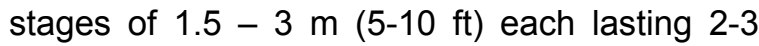
minutes to densify the sand above.

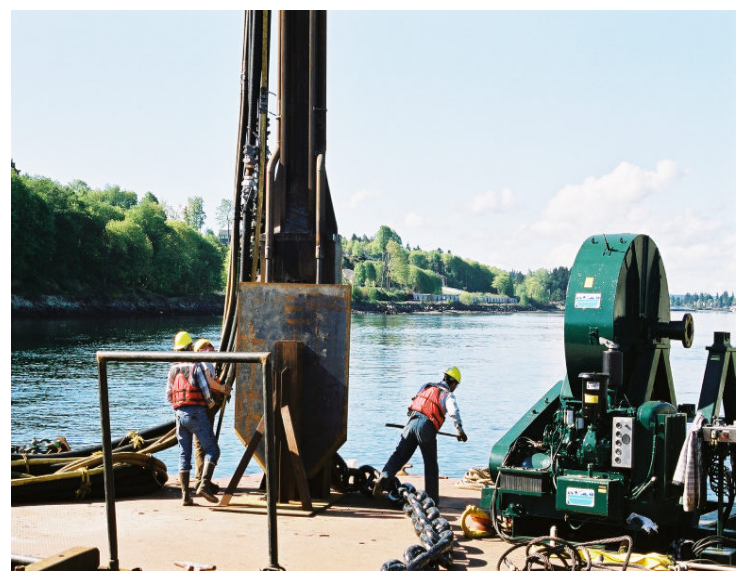

Figure 4. Hook up of Jet Hoses and Vibratory Hammer to Anchor

To validate the design, two full-scale test anchors were installed and tested using the equipment designed for the production anchors. The tests indicated the installation system is capable of driving the anchors to the required depth in 20 to 40 minutes, and confirmed the 4450 kN (1000 kip) holding capacity. See Figure 5.

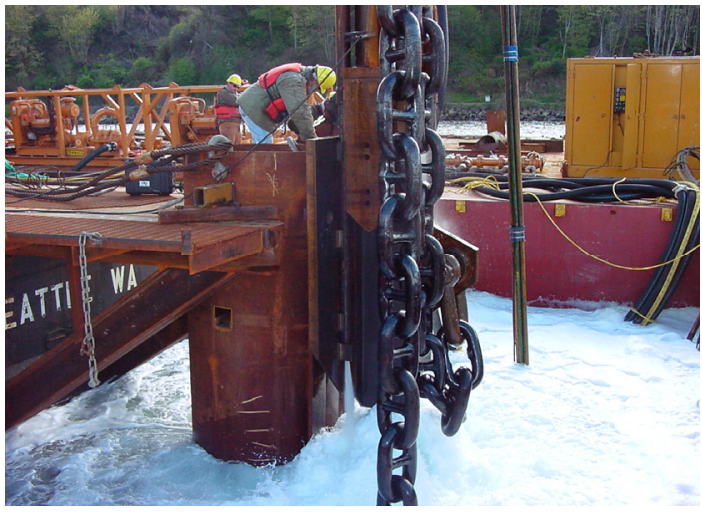

Figure 5. Installation of Anchors using water jets.

\section{ANCHOR LOAD TESTING}

Load testing the anchors is an integral part of the anchor installation. This causes the anchor to rotate and key in, thus positioning the anchor for maximum pull-out resistance, and minimizing any further displacement during operation. Load testing also verifies the anchor holding capacity. Load testing in sands can be carried out either vertically or horizontally since the anchor chain remains vertical throughout most of its embedded length. For this project, horizontal testing was used at first. Later on, vertical testing was used because it was faster.

With horizontal testing, two opposing anchors were pulled against each other using a loading mechanism on a barge located between the two. The chain from one anchor was fixed to the barge (the dead end), while the chain from the other anchor was connected to the end of a sliding block (the live end). The sliding block was connected to a winch via a 12-part block and tackle. First, tension was applied to remove any slack in the anchor chains; 220 to $310 \mathrm{kN}$ (50 to 70 kips) was required. Then, tension was slowly increased until one anchor broke loose, causing the tension in the anchor chain to fall off, indicating the anchor is keying. The drop in tension on one side caused the barge to move away from the keying anchor. This helps identify which anchor is keying first. After that, the tension started to build up again until the second anchor broke loose and the tension fell off again. After both anchors keyed, the tension was increased until the proof load was reached. For 
this project, the proof load was set at $4000 \mathrm{kN}$ (900 kip), slightly less than $50 \%$ of the ultimate capacity of the anchor.

To reasonably estimate the keying distance of each anchor, and therefore the final embedment depth, the following data was recorded during the tests. Line tension, indicates when the anchors slip, and when the proof load is reached. Amount of chain pulled in, indicates the total keying length (sum of both anchors), and if an anchor is pulling out. Barge movement, is the movement along the line between the anchors needed to proportion the total amount of chain pulled in to each anchor. Tidal elevation change, needed to adjust the amount of chain pulled in to determine the final embedment depth. Fig. 6 shows the data collected from one of these tests.

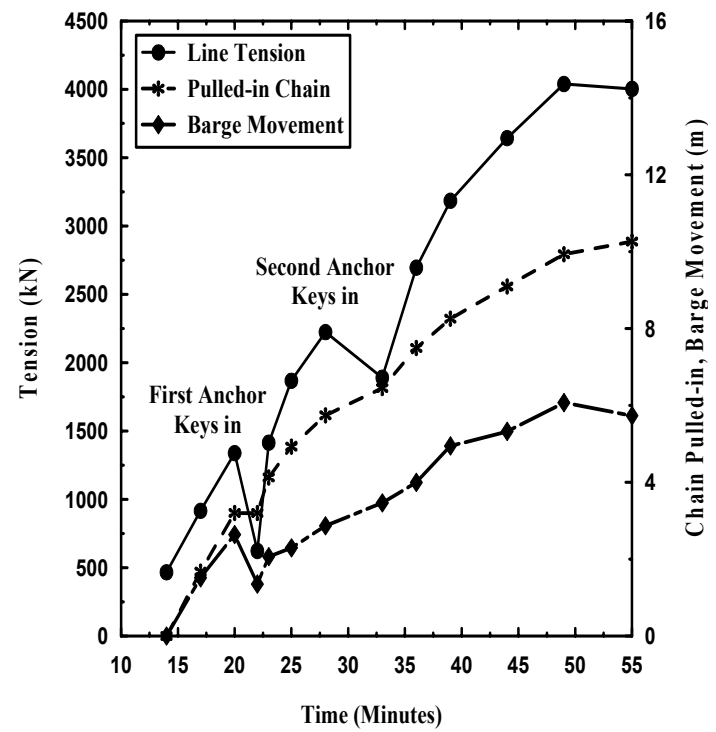

Figure 6. Horizontal Testing for Two plate Anchors

Vertical testing of one anchor at a time has proven more efficient because of the reduced maneuvering of the test barge, and simpler chain hook-up. With a vertical pull, there is less resistance from the chain embedded in the sand, thus the proof load can be reduced by about $20 \%$. For this project, the vertical tests were conducted to a proof load of $3560 \mathrm{kN}$ (800 kip). For these tests, the anchor chain ran over a roller installed on the end of the barge, and was then connected to the sliding end of the block and tackle. Counterweights were used to keep the barge relatively level during testing. Determining the final anchor embedment depth is simpler with vertical tests since all the chain pulled in comes from movement of the one anchor. Fig. 7 shows the results from vertical testing of two anchors, which represent the range of keying behavior encountered in this project.

All anchors were successfully tested to at least $3560 \mathrm{kN}$ (800 kip) with insignificant anchor movement at the final test load. Tests data indicate that the keying distance ranged from 2.0 to $7.3 \mathrm{~m} \mathrm{(6.5}$ to $24 \mathrm{ft}$ ), with most anchors keying

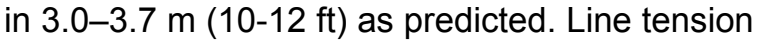
at keying ranged from 890 to $1780 \mathrm{kPa}$ (200 to 400 kips). Some anchors keyed-in suddenly while others keyed in gradually with little release of tension at each step. Differences in the keying behavior are attributed to variations in site conditions. Since the anchors are spread over a large area, soil conditions such as soil density and silt/clay content and the slope of the seabed vary from one location to another.

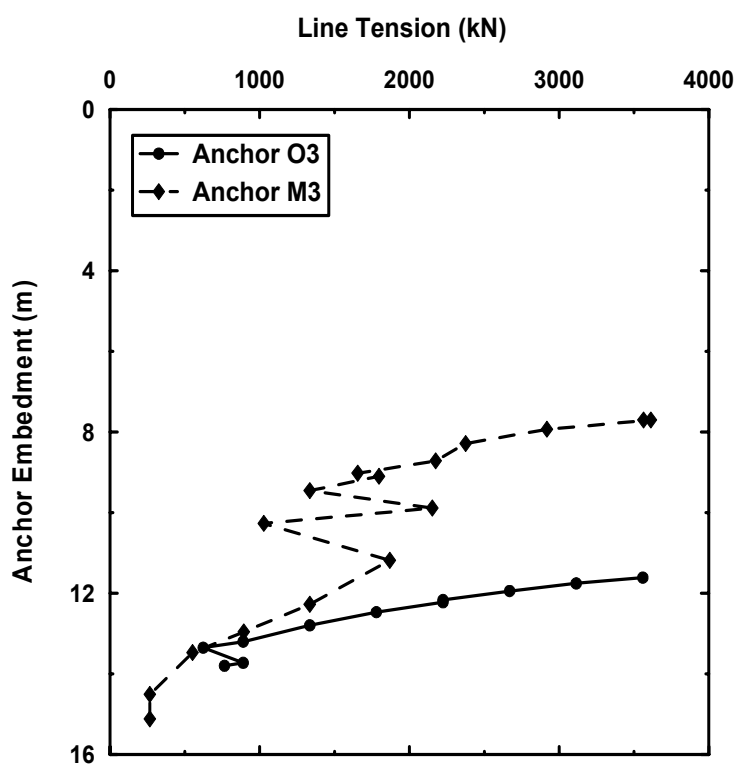

Figure 7. Vertical Testing of Plate Anchors

\section{CONCLUSIONS}

Driven plate anchors can be jetted in very dense sands to obtain high-holding-capacity anchors with significant cost savings over other anchor types. The challenge to the geotechnical engineer in such soil conditions is usually the prediction of anchor drivability, the effect of anchor installation on the keying behavior, and 
the final capacity of the anchor. The role of the geotechnical engineer starts by characterizing the site conditions and reasonably predicting the design parameters of the soil. Then he can determine the anchor geometry and required embedment depth, assess the anchor drivability, and help design the installation and testing methods and equipment.

Jetted-in driven plate anchors with a design capacity of 4450 kN (1000 kip) were successfully used in the construction of the New Tacoma Narrows Bridge. They held in place the large concrete foundation caissons in the deep and fast waters of the Narrows.

\section{REFERENCES}

Dicken, E.A. (1988). "Uplift behavior of horizontal anchor plates in sands". Journal of Geotechnical Engineering Division, ASCE, 114 (11), 1300-1317.

Forrest, J., Taylor, R. and Bowman, L. (1995). "Design Guide for Pile-Driven Anchors". Technical Report TR-2039-OCN, Naval Facilities Engineering Service Center, Port Hueneme, California.

Majer, E.L. (1955). "Zur Berechnung von Zugfundamenten". Osterreichische Bauzeitschrift, 10(5), 85-90 (in German).

Meyerhof, G. G., and Adams, J. I. (1968). "The ultimate uplift capacity of foundations". Canadian Geotechnical Journal, 5(4), pp 225-244

Row, P. W., and Davis, E. H. (1982). "The behavior of anchor plates in sand". Geotechnique, 32(1), London, England, 25-41.

Vermeer, P. A., and Sutjiadi, W. (1985). "The uplift resistance of shallow embedded anchors". Proceedings, $11^{\text {th }}$ International Conference on Soil Mechanics and Foundation Engineering, San Francisco, California, Vol. 3, 1635-1638.

Vesic, A. S. (1972). "Expansion of cavities in infinite soil mass". Journal of Soil Mechanics and Foundation Engineering Division, ASCE, 98 (SM3), 265-290. 